\title{
No trilho de uma carreira: oportunidades para jovens institucionalizados em centros educativos portugueses
}

\author{
Dulce Martins ${ }^{1}$, https://orcid.org/0000-0003-1429-0523
}

Carolina Carvalho', https://orcid.org/0000-0003-1793-2288

\begin{abstract}
Resumo
Os contextos de vida moderna trazem desafios que despertam o interesse de (re)pensar a importância e a forma de realizar um percurso para uma carreira. O objetivo do presente artigo é compreender como a frequência de cursos profissionais possibilita aos jovens institucionalizados em centros educativos portugueses uma exploração vocacional. Os jovens participantes $(\mathrm{N}=15)$ encontravam-se em cumprimento de medidas tutelares educativas, com a média de idades situada nos 16 anos de idade, a frequentar cursos de Educação e Formação de Adultos para aquisição de competências escolares e profissionais. As oportunidades disponíveis nos centros educativos portugueses promovem a caminhada dos jovens na educação e na responsabilidade através da frequência em atividades de educação e formação. É necessário dinamizar programas de intervenção para os jovens institucionalizados, para o desenvolvimento de um trilho para a vida ativa ancorado na realização e no equilíbrio positivo entre a vida pessoal e a carreira.
\end{abstract}

Palavras chave: Profissões; adolescentes; centros educativos.

\section{On the trail of a career: opportunities for institutionalized youngsters in Portuguese educational centers}

\begin{abstract}
The modern life setting brings forth challenges that instigate the interest of (re)considering the importance of a career and ways to achieve such goal. This paper aim is to deepen the understanding of opportunities of career exploration for institutionalized youngsters in Portuguese educational centers. Pursuant to the court's decision, the youngsters participants $(\mathrm{N}=15)$, with an average age of 16 years old, attended Adult Education and Training courses for the acquisition of academic and professional skills. The available opportunities in the Portuguese educational centers promote the youngsters path through education and responsibility by participating in educational and training activities. It is necessary to stimulate intervention programs for institutionalized youngsters, in order to develop a journey for the active life built upon the achievement and positive balance between personal life and a career.
\end{abstract}

Keywords: Occupations; adolescents; educational centers.

\section{En el sendero de una carrera: oportunidades para jóvenes institucionalizados en centros educativos portugueses}

\begin{abstract}
Resumen
Los contextos de vida moderna traen retos que despiertan el interés de (re)pensar la importancia y a la forma de realizar una trayectoria hacia a una carrera. El objetivo del presente artículo es comprender como la frecuencia de cursos profesionales posibilita a los jóvenes institucionalizados en centros educativos portugueses una exploración vocacional. Los jóvenes participantes $(\mathrm{N}=15)$ se encontraban en cumplimiento de medidas tutelares educativas, con un promedio de edades situada en los 16 años de edad, a frecuentar cursos de Educación y Formación de Adultos para adquisición de competencias escolares y profesionales. Las oportunidades disponibles en los centros educativos portugueses promueven la caminata de los jóvenes en la educación y en la responsabilidad a través de la frecuencia en actividades de educación y formación. Es necesario dinamizar programas de intervención para los jóvenes institucionalizados, para el desarrollo de un sendero para la vida activa anclado en la realización y en la satisfacción entre la vida personal y la carrera.
\end{abstract}

Palabras clave: Profisiones; adolescentes; centros educativos.

1 Universidade de Lisboa, Instituto de Educação - Lisboa - Portugal. 


\section{Introdução}

A escolha de uma carreira é um ato socialmente reconhecido e valorizado, que tem tido um renovado interesse no decorrer do século XXI. O interesse nesta temática deve-se provavelmente às mudanças sociais, culturais e económicas a que se vem assistindo. Os imperativos inerentes à globalização económica moldaram os contextos sociais e de vida dos indivíduos (Alves, 2006), sendo que as transformações sofridas caracterizam atualmente a sociedade moderna. Vários fatores como o género, a família, a falta de qualificações, o desemprego, numa sociedade multicultural, são exemplos que põem em causa o trilho de uma profissão e consequentemente o bem-estar dos indivíduos (Hirschi, 2012).

Face às transformações socioeconómicas e culturais, trilhar uma carreira contínua a ser importante no alcançar de uma posição pessoal e social na vida adulta. De tal forma importante que a imagem e a definição do próprio indivíduo continuam a depender largamente do trabalho ou profissão que possui (Super, 1953). Mas será a escolha de uma profissão uma das preocupações centrais para o domínio da Psicologia Vocacional? Qual a perspetiva teórica em voga que lhe dá enfoque? Como os jovens institucionalizados exploram o seu futuro profissional? Quais as oportunidades para os jovens institucionalizados? As respostas a estas questões ir-se-ão explorar ao longo deste texto.

Este texto resulta de uma investigação conducente a uma tese de doutoramento ${ }^{2}$, a qual integrou um projeto de investigação mais amplo ${ }^{3}$. O objetivo principal é dilucidar perspetivas teóricas atuais que sustentam a temática do desenvolvimento vocacional a par dos contextos de vida dos indivíduos jovens e aprendentes. Concretamente, o texto foca-se no exemplo dos jovens institucionalizados em centros educativos portugueses, na descrição dos seus contextos de vida institucional, de que forma estes são promotores de oportunidades, bem como as perceções que os jovens têm acerca da importância de desenvolver um trilho para a vida ativa e profissional.

\section{O trilho da carreira na perspetiva atual da psicologia vocacional}

Perspetivar e explorar percursos profissionais nem sempre foi tão complexo como é atualmente. As constantes mudanças societais relacionadas com os (des)ajustes económicos, culturais e tecnológicos influenciaram os modelos teóricos da Psicologia Vocacional, os quais evoluíram a par das necessidades de adaptação dos indivíduos aos contextos de trabalho.

2 Doutoramento em Educação, na especialidade Psicologia da Educação intitulado "Desenvolvimento da identidade vocacional de jovens institucionalizados em centros educativos portugueses".

3 Projeto Feedback, Identidade e Trajetórias Escolares: Dinâmicas e Consequências (PTDC/CPE-PEC/121238/2010), financiado pela Fundação para a Ciência e Tecnologia (FCT) de Portugal, tendo sido desenvolvido no Instituto de Educação da Universidade de Lisboa.
De acordo com Alves (2012), os indivíduos a partir do século $X X$, em particular após a segunda guerra mundial, viveram progressivamente a destruturação do mercado de trabalho. Ainda assim, no passar do século $X X$, os indivíduos foram contando com trajetórias profissionais seguras em que ocupavam empregos permanentes, nos quais Ihes era possível desenvolver carreiras em contexto das organizações (Savickas, 2012; Duarte, 2009). Contudo, a partir do século $\mathrm{XXI}$, com a chegada da revolução digital e as novas formas do capitalismo mundial, nomeadamente a flexibilização do uso do capital e do trabalho, implicaram precarização e o aumento do desemprego. Concretamente, os efeitos sentidos em relação à incorporação do trabalho intelectual, no qual o indivíduo deixou de ser mediador do processo de produção, passando a sujeito e ator do mesmo (Amorim, 2013).

Num contexto económico em que as organizações empresariais reestruturaram o uso do capital e do trabaIho, em que a mão-de-obra passou a ser qualificada, para integrar um posto de trabalho (Alves, 2012), e os custos associados foram drasticamente reduzidos, o mercado de emprego passou a ser instável e temporário. Neste sentido, tornaram-se crescentes as exigências de qualidades técnicas e individuais dos sujeitos em termos de adaptabilidade e flexibilidade às situações e contextos de trabalho. A inevitabilidade da "precarização do mercado de trabalho, a individualização, o declínio do trabalho pago, o sentimento crescente de insegurança" (Alves, 2012, p.7) surgiu como fator decisivo para o despoletar de uma nova era societal em torno do mundo do trabalho.

O (des)equilíbrio da vida profissional repercutiu-se na vida pessoal e familiar dos indivíduos, nas quais se tornou fundamental (re)pensar competências e aspirações (Duarte \& cols., 2010). Surgiu, a necessidade de apoiar os indivíduos a perspetivar e a desenvolver as suas carreiras, não só em contexto laboral como era usual, mas a par de uma vida pessoal e familiar. $\mathrm{Na}$ atualidade, o desenvolvimento e gestão de carreira requer uma perspetiva de vida no "mundo pós moderno delineado por uma economia global e apoiado pela tecnologia da informação" (Duarte \& cols., 2010, p. 394). Isto é, no reflexo à época presente, a chamada era moderna líquida (Bauman, 2001; Guichard, 2012), é tarefa da Psicologia Vocacional apoiar os indivíduos a perspetivar e a refletir as suas trajetórias de vida. Concretamente, ajudá-los a progressivamente projetar e construir as suas próprias vidas, incluindo seus percursos profissionais (Duarte \& cols., 2010). No trilho destes percursos a satisfação no contexto de formação profissional pode ser entendida como um sentimento de identificação, ajustamento à área de formação traduzida em termos de bem-estar e comprometimento (Bradagi, Lassance, Paradiso, \& Menezes., 2006).

Numa perspetiva mais abrangente e contextualizada às exigências do século $X X I$, a resposta à pergunta "o que vou ser?" ou "o que vou fazer da minha vida?" contínua a ser uma das preocupações centrais dos indivíduos. Mais que encontrar uma resposta para a profissão, um dos objetivos da Psicologia Vocacional centra-se na preocupação ancestral, de ajudar os indivíduos perante a adversidade a 
desenvolver a busca de sentido para as suas vidas (Frankl, 1988), como processo englobado num ciclo de vida (Savickas, 2012). Por outras palavras, atualmente, a Psicologia Vocacional tem o papel de ajudar os indivíduos a encontrar as melhores possibilidades de acordo com os seus interesses e competências, perante as situações contextuais, numa ótica de aprendizagem ao longo da vida. Como refere Andrade, Meira e Vasconcelos (2002), esta orientação deve acompanhar o processo educativo, cooperando com ele e não apenas suprindo suas possíveis carências.

É no decurso das trajetórias de vida que a ocorrência de novas relações entre os indivíduos "trabalhadores e o mundo do trabalho originaram a necessidade de se desenvolver e aplicar novos dispositivos de promoção pessoal" (Duarte \& cols., 2010, p. 395). Isto é, diante dos desafios (e.g., ter novo emprego, nova experiência de aprendizagem) ou riscos que se podem encontrar (e.g., desemprego, trabaIho a tempo parcial ou temporário, divórcio), os indivíduos deverão encarar essas situações como oportunidades de aprendizagem e de reflexão para se envolverem no delinear de um projeto pessoal de Life Design (Savickas \& cols., 2009) ou Construção da Vida (Duarte \& cols., 2010). Nas palavras de Duarte (2009):

A carreira do indivíduo é vista, agora, como um fiel registo da vida de cada um, deriva da maneira como ele capta a realidade e a ela se adapta, sem de algum modo atraiçoar a sua essência, ou seja, os traços essenciais da sua personalidade e as linhas estruturantes da sua história pessoal - que, como qualquer obra do espírito humano, é única e irrepetível (p.12)

\section{Life Design: o paradigma do construção do eu e da carreira}

Life Design o recente paradigma da Psicologia Vocacional (Savickas \& cols., 2009). Este paradigma foi proposto na publicação de Mark Savickas e seus colaboradores no ano de 2009. O modelo vigente baseia-se nas "teorias de construção do Self (Guichard, 2005) e da construção da carreira (Savickas, 2005) que descrevem o comportamento de carreira e seu desenvolvimento. Assim, a estrutura geral está organizada de maneira a considerar todo o ciclo de vida, a ser holística, contextual e preventiva" (Savickas \& cols., 2009, p. 244). De acordo com Savickas (2012), este modelo de intervenção de carreira entendido na língua portuguesa por paradigma da construção da vida (Duarte \& cols., 2010), não substitui os paradigmas anteriores, de orientação vocacional e de construção de carreira, postos em prática nas últimas décadas, mas sim posiciona-se paralelamente.

O trabalho recentemente publicado por Savickas (2012) caracteriza o Life Design como o paradigma para a intervenção de carreira no século XXI.O autor considera a intervenção de carreira segundo a perspetiva do construcionismo social, onde os indivíduos são autores das suas experiências, caracterizados por histórias autobiográficas, com as quais podem ser ajudados a refletir sobre temas de vida e, por sua vez, construir as suas carreiras (Martins, 2015). Neste sentido, o novo paradigma assenta na necessidade de mudança nos modelos de carreira e métodos de aconselhamento levados a cabo anteriormente. Contudo, como já referido anteriormente, os paradigmas anteriores poder-se-ão continuar a dinamizar. Como por exemplo, Martins (2015), refere que os profissionais e agentes educativos (e.g., professores, psicólogos) mediante os seus jovens ou alunos poderão aplicar intervenções de carreira que reflitam abordagens aos diferentes paradigmas. Concretamente, e de acordo com as necessidades diagnosticadas nos jovens, a orientação vocacional para identificar ajuste ou desajuste ocupacional, educação para a carreira para promover o desenvolvimento da identidade vocacional, ou construção da vida, que como o próprio nome indica para construir uma vida relacionada com uma carreira (Savickas, 2012).

Life Design é um paradigma, fruto do conhecimento evolutivo presente nas perspetivas teóricas de construção e desenvolvimento vocacional e de carreira. Reflete o atual estado das problemáticas e dos desafios socioeconómicos e culturais que os indivíduos estão expostos na construção da vida pessoal em consonância com o mundo trabalho e em contextos diversificados. Esta nova designação atualiza o conceito de construção de carreira, aproximando-o ainda mais à noção de vida moderna face à adaptação, flexibilidade e gestão das dinâmicas socioeconómicas que ocorrem continuadamente na vida dos indivíduos (Martins, 2015). É um modelo teórico que acentua a importância de "dar sentido à vida", para melhor compreender e lidar com as características dinâmicas e contextuais em que os indivíduos se inserem (Taveira, 2011, p. 73).

\section{Pressupostos do paradigma Life Design}

O desenvolvimento do paradigma Life Design formaliza o seu objetivo para ajudar os indivíduos no processo da construção da vida, alicerçando-se sob cinco pressupostos, designadamente: (1) dos traços e estados ao contexto, (2) da prescrição ao processo, (3) de uma causalidade linear às dinâmicas não lineares, (4) dos fatos científicos às realidades narrativas e (5) da descrição à modelagem (Duarte \& cols., 2010; Savickas \& cols., 2009).

Segundo os autores deste modelo (Savickas \& cols., 2009), os cinco pressupostos foram delineados a pensar em "produzir conhecimento e capacidades específicas para analisar e lidar com contextos ecológicos, dinâmicas complexas, causalidades não-lineares, realidades subjetivas múltiplas e modelagem dinâmica" (p. 242). Com efeito, trata-se de um modelo delineado para programas de intervenção para o aconselhamento acerca das trajetórias de vida dos indivíduos integradas na vida social do trabalho.

Passando a descrever os cinco pressupostos ${ }^{4}$, o primeiro "dos traços e estados ao contexto "alerta para o

4 Para mais consulta, ver os trabalhos originais de Savickas e cols. (2009) e Duarte e cols., (2010). 
fato de que o aconselhamento deve ter em consideração a história de vida dos indivíduos e o contexto sociocultural que ocupa(va)m. O indivíduo "forma uma entidade dinâmica complexa, que resulta de uma auto-organização de adaptação mútua ao longo do tempo" (Duarte \& cols., 2010, p. 396). O segundo pressuposto, "da prescrição ao processo", sublinha as mudanças sofridas nos modelos de construção de carreira sob a necessidade dos "conselheiros" ajustarem uma comunicação baseada no "como fazer" e não "o que fazer". Ou seja, “... desenvolver estratégias eficientes de resolução de problemas, de planeamento da ação e da construção de vida como um todo" (Duarte \& cols., 2010, p. 397). O terceiro pressuposto, "de uma causalidade linear às dinâmicas não lineares", refere ser necessário os "conseIheiros" terem em consideração que os interesses e aptidões não são suficientes para garantir o sucesso num emprego ou formação, uma vez que não se podem considerar como elementos de vida permanentes. Por sua vez, os métodos ou a metodologia de aconselhamento devem adotar estratégias de resolução de problemas em contato direto com o contexto sociocultural que os indivíduos ocupam, devendo ser um processo "repetido de forma interativa a fim de se formular soluções sustentáveis e satisfatórias" (Duarte \& cols., 2010, p. 397).

O quarto pressuposto, "dos factos científicos às realidades narrativas", assenta no construtivismo dialético, entre a análise das narrativas que o indivíduo faz das múltiplas realidades subjetivas e o seu ecossistema (Cardoso, 2011). Por outras palavras, é o foco na contínua (re)construção dos indivíduos, baseada nas histórias autobiográficas, " na busca de sentido que os capacitarão a construir uma nova visão sobre si mesmos" (Duarte \& cols., 2010, p. 398). O quinto e último pressuposto, "da descrição à modelagem", propõe que é necessário englobar neste modelo de aconselhamento um processo que seja adaptado a cada indivíduo e que se evitem os processos de aconselhamento padronizados (e.g., testes psicológicos, resultados meramente estatísticos). $\mathrm{O}$ foco é na modelagem integrada no comportamento humano que guie e confira intencionalidade, onde o indivíduo deve envolver-se em atividades e experiências que façam parte das suas narrativas de vida (Savickas \& cols., 2009).

Os cinco pressupostos sumariamente apresentados constituem uma nova abordagem para as intervenções de carreira. Life Design é um modelo teórico que engloba os cinco pressupostos sob a perspetiva do construcionismo social, que posiciona os indivíduos como autores do processo das narrativas (auto)biográficas para construírem as suas carreiras (Savickas, 2012).

\section{Jovens institucionalizados: caminhando nas oportunidades da Educação e da responsabilidade}

Nas sociedades ocidentais, a definição de jovens institucionalizado tem estado associada à resposta do sistema de jurisdição de menores para proteção dos que se encontrem em situações de risco (e.g., violência física/psico- lógica, abuso ou negligência emocional) (Calheiros, Garrido, Lopes, \& Patrício, 2015). O processo de institucionalização de jovens é considerado um modelo de proteção social, com a finalidade de zelar pela segurança e bem-estar destes em instituições especializadas (Amado, Ribeiro, Limão, \& Pacheco, 2003). Concretamente, para garantir direitos de preservação de igualdade, independentemente da condição socioeconómica ou cultural, género, religião, nacionalidade, incapacidade física, ou qualquer outra situação, quer pelas instituições públicas ou privadas, quer pelos tribunais (Souto, 2010).

A institucionalização de jovens é entendida e estabelecida sob um plano democrático. Fruto da evolução das dinâmicas conjunturais políticas e socioeconómicas e, em particular, da definição e desenvolvimento de padrões mínimos internacionais dos direitos humanos. Em especial, com a Convenção das Nações Unidas sobre os Direitos da Criança (adotada em 1989 e ratificada por Portugal em 1990) o direito internacional procurou consagrar a proteção das crianças (Martins \& Carvalho, 2013). No âmbito da Convenção, a própria definição de criança passou a ser delimitada até aos 18 anos de idade (Pacheco, Pestana, Figueiredo, \& Martins, 2014). Neste texto recorre-se à designação de jovens ao invés de crianças, seguindo a ideia mais abrangente de que jovens designa um conceito socialmente construído, que se caracteriza como etapa de socialização, imerso em dinâmicas e processos transitórios da adolescência para a vida adulta, refletindo experiências com diversos agentes, entre os quais se salientam a família, os pares, a escola e outras instituições (Pais, 1999). Neste sentido, jovens pode designar indivíduos com idade igual ou superior aos 18 anos de idade, podendo até integrar o que Levinson (1990) caracterizou como o período inicial da fase vida de um jovem adulto (a partir dos 20 anos).

Jovens institucionalizados definem-se diante da condição de um grupo de indivíduos estar sob um plano de intervenção, aos cuidados de uma instituição especializada, com carácter de alojamento permanente, com profissionais qualificados (Calheiros \& cols., 2015) para cumprir meticulosamente regras, horários e programas educacionais. O ambiente institucional caracteriza a condição dos jovens institucionalizados e define-se na organização e em dinâmicas funcionais próprias (Sloutsky, 1997). Organização e dinâmicas funcionais proporcionam aos jovens institucionalizados a aquisição de competências para a vida ativa e responsável, através da utilização de programas e métodos pedagógicos (Martins, 2015).

De acordo com o quadro normativo português, a condição de jovens institucionalizados dimensiona-se para(a) a promoção e proteção de indivíduos vítimas de maus tratos e/ ou negligência e (b) para aqueles que cometem atos tipificados pela lei como crime (Martins, 2015). É sobre esta última dimensão da institucionalização de jovens que o presente texto mais se dedica, referindo-se, em seguida, a sua contextualização em Portugal. 
Os jovens institucionalizados em centros educativos portugueses ${ }^{5}$, são na generalidade menores de idade, identificados com trajetórias de risco ou de delinquência. A institucionalização de jovens em centros educativos inscreve-se nas normas de direito internacional e no propósito da (re) educação e reinserção de jovens que praticaram atos qualificados pela lei vigente como crime (e.g., crimes contra o Património; contra a propriedade vários tipos de roubo e furto; contra as Pessoas, com vários tipos de ofensas à integridade física) (Martins \& Carvalho, 2013).

Importa, desde já, referir que os centros educativos, são estabelecimentos que estão sob o domínio do Ministério da Justiça, na dependência orgânica e hierárquica dos serviços da Direção Geral de Reinserção e Serviços Prisionais, com carácter de intervenção educativa e pedagógica, associada à decisão judicial de internamento.

Os jovens identificados com práticas tipificadas de crime, em garantia dos seus direitos civis e sociais, são guiados pelos princípios de legalidade presentes na Lei Tutelar Educativa (LTE, Lei n 166/99, de 14 de Outubro, 1999) em vigor desde 2001. De acordo com Martins (2015):

Com a entrada em vigor da LTE há a distinção legal entre menores em perigo e menores infratores ou delinquentes. Para os menores infratores ou mesmo delinquentes, que têm comportamentos considerados criminosos, a intervenção tutelar atua nos casos em que o Estado se encontra legitimado para (re)educar o menor, com ou sem aprovação de quem detém o poder paternal, como é o caso da institucionalização por internamento em centro educativo (p. 22)

A LTE (Lei n 166/99, 1999) é aplicada ao menor que com idade compreendida entre os 12 e os 16 anos, ou que não tenha completado 18 anos de idade, aquando da decisão jurídica em primeira instância, através de Medidas Tutelares Educativas (MTE), cujo cumprimento "pode prolongar-se até o jovem completar 21 anos, momento em que cessa obrigatoriamente" (LTE, 1999, art.5²).As TEM visam garantir a educação os jovens "para o direito e a sua inserção, de forma digna e responsável, na vida em comunidade" (Lei $n^{\circ}$ 166/99, 1999, art.2 n $\left.^{\circ} 1\right)$.

De acordo com a LTE (Lei n 166/99, 1999) "As causas que excluem ou diminuem a ilicitude ou a culpa são consideradas para a avaliação da necessidade e da espécie de medida (art.11 $\left.{ }^{\circ}, \mathrm{n}^{\circ} 2\right)$. Assim, de entre as várias MTE contempladas na LTE, a de internamento (Lei n 166/99, 1999, art. $11^{\circ}$ ) em centro educativo é a que corresponde à medida mais gravosa para o direito de menores, manifestada na prática de facto subsistente no momento da decisão judicial. Por outras palavras, "visa proporcionar ao menor, por via do afastamento temporário do seu meio habitual e da utilização de programas e métodos pedagógicos, a interiorização de valores conformes ao direito e a aquisição de recursos que lhe permitam, no futuro, conduzir a sua vida de modo social e juridicamente responsável" (Lei n 166/99, 1999, art. 17º n 1).

5 Para consulta mais detalhada ver: http://www.dgrs.mj.pt/web/rs/estat
A LTE prevê que a MTE de internamento em centro educativo, pode abranger (a) medida cautelares de guarda, (b) internamento para realização de perícia sobre a personalidade (quando assim é incumbido pela jurisdição de menores), (c) o cumprimento da detenção e (d) o internamento em fins-de-semana (Martins, 2015). A execução da MTE de internamento em centro educativo é disposta em regime aberto, semiaberto ou fechado ${ }^{6}$, os quais estabelecem maior ou menor grau de abertura ao meio sociocultural dos jovens.

De acordo com a LTE, os jovens institucionalizados em centros educativos portugueses têm direitos e deveres inerentes à sua condição. Apesar do caráter coercivo e impositivo da lei, os jovens têm, entre outros aspetos, a garantia do direito de continuar um percurso educativo, de contatar pontualmente com as suas referências afetivas (e.g. amigos, familiares) e uma vez que são menores de idade ao cuidado do Estado, o direito e o dever, simultaneamente, de frequentar atividades de educação e formação para desenvolvimento de competências pessoais, sociais e profissionais.

\section{Educação para uma futura carreira}

A educação dos jovens institucionalizados em centros educativos portugueses é assegurada através da realização de um Plano Educativo Pessoal (PEP), assim que o jovem é institucionalizado com medida de internamento em centro educativo. Neste PEP deve constar a avaliação das necessidades de formação, em matéria de educação cívica, escolaridade, preparação profissional, ocupação útil dos tempos livres, bem como a frequência da escolaridade obrigatória (Lei n 166/99, 1999, art.171. ${ }^{\circ}$ ). Os PEP tem o propósito de assegurar aos jovens atividades de cariz de educação e formação, sendo elaborados em conformidade com a duração e regime de execução da MTE, bem como com as suas particulares motivações, necessidades educativas e de reinserção social (Lei n 166/99, 1999, artigo 164", $\mathrm{n}^{01}$ ). De acordo com o Regulamento Geral e Disciplinar dos Centros Educativos (Decreto-Lei no 323-D/2000, de 20 de Dezembro, 2000), o PEP, na sua realização e avaliação de progresso, conta com a colaboração dos próprios jovens, familiares, representantes legais ou a pessoa que detenha a guarda de facto do jovem, bem como um técnico tutor pertencente ao centro educativo, onde o jovem se encontrar internado (Decreto-Lei $n^{\circ} 323-\mathrm{D} / 2000$, art. $21 .^{\circ}$ e $22^{\circ}$ ).

A aplicação do PEP em termos de atividades de frequência escolar é concretizada através da oferta de cursos de cariz profissionalizante, os cursos de Educação Formação de Adultos (cursos EFA). Estes cursos foram criados, em 2000, para desenvolver conhecimentos e qualificações técnicas nos indivíduos adultos que detinham défices de escolarização e qualificações profissionais (Quintas, 2008, p.93). Contudo,

6 Para aprofundar a informação sobre as características dos três tipos de regime de execução de MTE de internamento em centro educativo, consultar a LTE em: http://www.pgdlisboa.pt/leis/lei_ mostra_estrutura.php?tabela=leis\&artigo_id $=542$ A0043\&nid $=542 \& n v$ ersao $=\&$ tabela $=$ leis) 
face à necessidade de Portugal, no quadro da União Europeia, promover o sucesso educativo e prevenir os diferentes tipos de abandono escolar, nomeadamente nas idades mais jovens, os cursos EFA passaram-se a adequar aos jovens com idade igual ou superior a 15 anos (Martins, 2015).

Os cursos EFA têm como principal objetivo fornecer habilitações escolares a par de competências profissionais, para promoção da (re)inserção dos jovens no mercado de trabalho. Isto é, conferem a possibilidade de dupla certificação, académica e profissional, sendo o seu modelo de formação divido em duas categorias, a formação base (e.g., Cidadania e Empregabilidade, Linguagem e Comunicação, Matemática para a Vida e Tecnologias da Informação e Comunicação, Inglês como língua Estrangeira) e a formação tecnológica (e.g., formação prática, normalmente simulada, em variadas áreas profissionais: pintura e construção civil, cozinha, informática).

A organização dos cursos EFA é resultado de um curriculum diferenciado composto por uma tipologia de formação de equivalência ao nível de Ensino Básico, ministrado em Portugal. Isto é, ao nível do $1^{\circ}, 2^{\circ}$ e $3^{\circ}$ ciclos do Ensino Básico, (conhecido como tipo B1, B2, B3 e, mais recentemente, contempla igualmente o Ensino Secundário), fornecendo a aquisição de certificados escolares que correspondem aos respetivos níveis de aprendizagem. Neste sentido, importa referir que o funcionamento escolar do Ensino Básico nestas instituições tem sido, desde 1978, assegurado pelo Ministério da Educação, através das direções regionais de educação. Os cursos são ministrados por professores que exerçam funções nos estabelecimentos públicos dos Ensinos Básico e Secundário. Concretamente, os conteúdos da formação base são maioritariamente assegurados por professores e os da formação tecnológica por formadores detentores de certificado de aptidão pedagógica (Martins, 2015). Com efeito, a organização e o desenvolvimento do curriculum e das ofertas formativas são da responsabilidade do Ministério da Educação. Mas a acreditação e certificação das competências adquiridas competem ao Centro Protocolar de Formação Profissional para o Sector da Justiça, a entidade formadora que assegura a oferta educativa e formativa em causa, de acordo com as disposições legais vigentes para cada nível e modalidade de ensino ou formação (Despacho n. ${ }^{\circ}$ 23038/2009, 2009, n 8).

Nos centros educativos a modalidade de educação e formação através da frequência obrigatória de cursos EFA, garante a possibilidade de continuação da trajetória escolar que os jovens interromperam aquando o seu internamento. O envolvimento escolar dos jovens, no âmbito da formação profissional, cria condições para adquirir conhecimentos especializados para o desempenho de uma profissão e para uma (re)inserção social que se pretende integral (Martins, 2015; Martins \& Carvalho, 2013; Pacheco \& cols., 2014).

\section{Método}

O objetivo do presente artigo foi compreender como a frequência de cursos profissionais EFA possibilita aos jovens institucionalizados em centros educativos portugueses uma exploração vocacional. Por serem são menores de idade e ao cuidado do Estado têm o direito e o dever, simultaneamente, de frequentar atividades de educação e formação com o objetivo de desenvolver competências pessoais, sociais e profissionais.

\section{Participantes}

Participaram neste estudo 15 jovens, entre os 14 e os 18 anos de idade $(M=16.5, D P=1.06)$, institucionalizados em cinco centros educativos portugueses. Os participantes eram todos do sexo masculino a frequentar diferentes cursos EFA de tipologia B2 e B3.

\section{Instrumento}

Foi elaborado um guião para a realização de entrevistas para facilitar o processo de recolha de informação. Para este texto, os dados que se apresentam são extraídos das vozes dos jovens, em torno da seguinte questão: Considera que o que está a aprender o poderá ajudar a escolher uma via profissional?

\section{Procedimento}

As entrevistas decorreram em contexto institucional de cinco centros educativos portugueses, para as quais se obtiveram as devidas autorizações da Direção Geral da Reinserção e Serviços Prisionais, dos centros educativos e dos jovens participantes no estudo. Participaram neste estudo 15 jovens no total, uma vez que, à data da realização do estudo, eram os jovens que estavam institucionalizados nos centros educativos e que se disponibilizaram a colaborar.

Partindo do consentimento informado e da garantia de salvaguarda do direito à privacidade de todos os jovens e profissionais intervenientes nos centros educativos, as opiniões dos jovens participantes foram audiogravadas para posterior transcrição e análise de conteúdo. Todas as entrevistas decorreram em espaços calmos e reservados e os nomes dos jovens foram codificados para identificação posterior com designações alfanuméricas.

Os dados obtidos nas entrevistas são "descritivos na linguagem do próprio sujeito, permitindo ao investigador desenvolver intuitivamente uma ideia sobre a maneira como os sujeitos interpretam aspectos do mundo." (Bogdan \& Biklen, 1994, p. 134). Procedeu-se à análise de conteúdo para descoberta indutiva dos significados expressos pelos jovens participantes. Neste processo de análise de conteúdo, adotou-se um critério semântico de semelhança de conteúdo, para a identificação das categorias e subcategorias, a partir das unidades de registo (Bardin, 2011). Para o efeito, recorreu-se ao programa Nvivo na sua versão 10. 


\section{Resultados}

Dos 15 jovens participantes, onze eram de nacionalidade portuguesa, três nascidos em Cabo Verde e um na Roménia. Nove jovens estavam em cumprimento da MTE de internamento em regime semiaberto, cinco em regime fechado, e um em regime aberto.

As trajetórias de vida biográfica dos jovens participantes acusam vivências familiares instáveis e destruturadas, quer a nível emocional como económico, na maioria monoparentais $(n=10)$, nas quais os pais dos jovens são caracterizados com dificuldades de orientar e supervisionar os filhos. Em relação ao percurso escolar antes da institucionalização, os jovens participantes revelaram ter uma trajetória irregular, aquém do esperado para as suas de idades no momento do estudo $(M=16.5)$. As razões apontadas centram-se nas várias retenções e falta de interesse em relação à escola.

A execução das MTE tinham uma duração entre os oito e os 36 meses e à data da realização das entrevistas os jovens cumpriam as MTE há pelo menos três meses, sendo o máximo de tempo registado de um ano e meio de internamento em centro educativo.

Estando a maioria dos jovens $(n=9)$ em regime de execução semiaberto da MTE, para além das atividades educacionais e de lazer no centro educativo, em alguns casos, os jovens estavam autorizados a sair do centro para passar o fim de semana com a família.

Os motivos qualificados como crime, puníveis por lei, que ditaram a decisão judicial de internamento em centro educativo foram (a) crimes por ofensa à integridade física, (b) por furto ou roubo, (c) por violação e (d) homicídio qualificado. A maioria dos jovens participantes $(n=8)$ apresentava MTE anteriores às medidas que estavam a cumprir. Como por exemplo, medidas cautelares de guarda e medidas de acolhimento noutras instituições.

Todos os jovens participantes $(\mathrm{N}=15)$ estavam a frequentar cursos EFA de tipologia B2 e B3, para equivalência ao $2^{\circ}$ e $3^{\circ}$ ciclos do Ensino Básico, bem como para certificação de uma qualificação em vários ramos profissionais. Con- forme indica a Figura 1, os cursos EFA de tipologia B2, conferiam certificação nos ramos profissionais de Jardinagem e Pintura e Construção Civil (PCC). Por seu turno, os cursos EFA de tipologia B3, os mais frequentados, possibilitavam a certificação em Operador de Manutenção Hoteleira (OMH), Eletricidade de Instalações (EI), Instalador e Reparador de Computador (IRC), Marcenaria, Serralharia e Empregado de Mesa (EM).

Das vozes dos jovens participantes entrevistados à pergunta "Considera que o que está a aprender o poderá ajudar a escolher uma via profissional?", encontraram-se categoria e subcategorias no decorrer do processo de codificação indutivo ao discurso dos jovens. Partindo da análise do discurso dos jovens participantes, constituíram-se as unidades de registo e, por sua vez, os conceitos emergentes para o processo de categorização e subcategorização. Com efeito, apresenta-se a Tabela 1, onde por semelhança de conteúdo se estabeleceram as frequências das ocorrências nas subcategorias.

De acordo com as categorias e subcategorias presentes na Tabela 1, os jovens participantes avaliaram os cursos EFA frequentados, relativamente ao seu interesse, utilidade, desinteresse e indecisão para integrar uma futura profissão.

Em relação ao interesse no curso frequentado, alguns jovens participantes revelaram a opinião de que o curso integrava os seus objetivos pessoais de vida para um futuro profissional, dizendo simplesmente que "sim" (8A, 18 anos, Curso EFA B3 EM) e "Sim, é o que eu quero. E costuma haver trabalho" (5A, 16 anos, curso EFA B3 Cozinha). A afirmação deste jovem participante, igualmente revelou a utilidade do curso que frequentava, no que concerne encontrar trabalho no ramo profissional para o qual estava a ser formado, sendo neste caso o curso de cozinheiro. Com a mesma opinião, em termos de utilidade do curso como forma de conseguir trabalho, três jovens disseram:

Sim vai-me ajudar. Penso que posso seguir a vida de cozinheiro (4A, 14 anos, curso EFA B3 Cozinha)

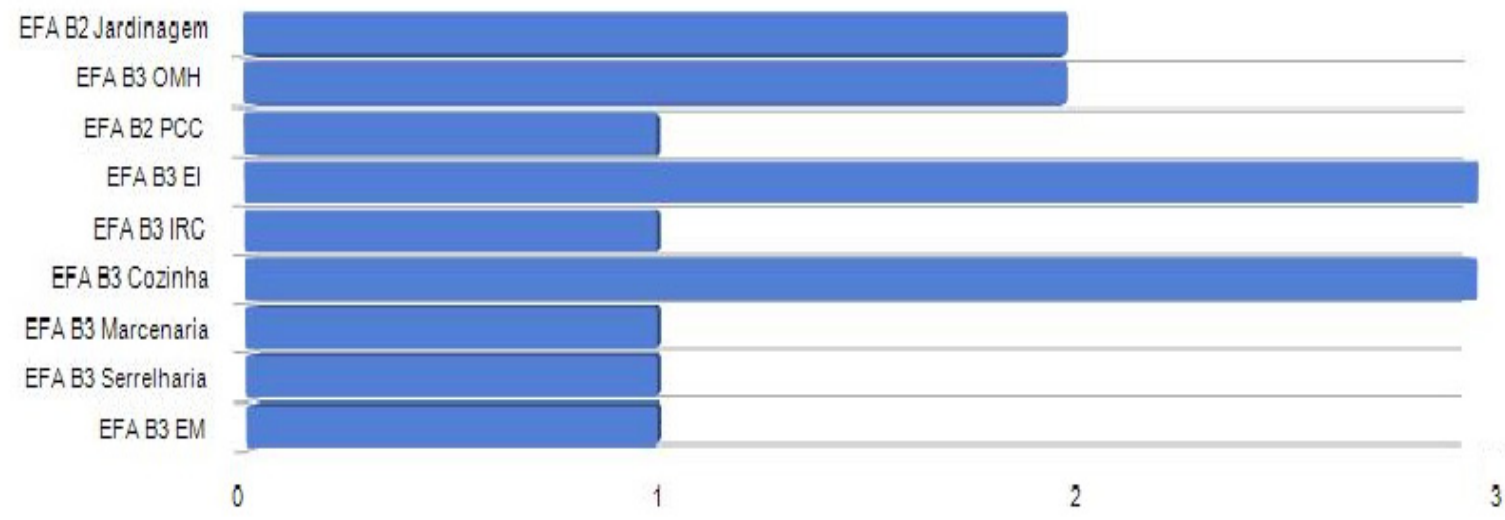

Figura 1. Cursos EFA frequentados pelos 15 jovens participantes. 
Tabela 1. Categoria e subcategorias emergentes do discurso dos jovens participantes.

\begin{tabular}{|c|c|c|}
\hline Categoria & subcategorias & Conteúdo temático \\
\hline \multirow{6}{*}{ Avaliação dos cursos } & $\begin{array}{l}\text { Interesse } \\
\quad(n=2)\end{array}$ & $\begin{array}{l}\text { Curso que integra os objetivos definidos para um } \\
\text { futuro profissional }\end{array}$ \\
\hline & \multirow{3}{*}{$\begin{array}{l}\text { Utilidade } \\
\qquad(n=8)\end{array}$} & Forma de conhecer outros cursos e profissões \\
\hline & & Forma de completar o percurso escolar interrompido \\
\hline & & Forma de conseguir trabalho no futuro \\
\hline & $\begin{array}{l}\text { Desinteresse } \\
\qquad(n=1)\end{array}$ & $\begin{array}{l}\text { Curso que não integra os objetivos definidos para um } \\
\text { futuro profissional }\end{array}$ \\
\hline & $\begin{array}{l}\text { Indecisão } \\
\quad(n=8)\end{array}$ & Sem definição de objetivos profissionais \\
\hline
\end{tabular}

Sim, é um curso em que ainda se consegue arranjar trabalho (1C, 18 anos, Curso EFA B2 PCC)

Sim e tem saída (29E, 16 anos, Curso EFA B3 IRC)

Em termos de utilidade, mas associada à forma de completar o percurso escolar interrompido, um jovem respondeu que considera útil para “... ficar com o $9^{\circ}$ Ano de escolaridade"(10B, Curso EFA B2 Jardinagem).

Outras opiniões avaliativas dos cursos EFA surgiram, nomeadamente de desinteresse e indecisão para escolha de uma futura profissão. Relativamente ao desinteresse apenas um jovem respondeu que não se perspetivava a fazer profissionalmente o curso que estava a frequentar, dizendo: "Não, não me imagino a fazer nada disto" (4C, 16 anos, Curso EFA B3 EI).

Quanto às opiniões relativas à indecisão, várias perceções foram reveladas. Concretamente:

Não sei, penso que ainda é cedo para saber isso (31A, 16 anos, Curso EFA B3 Cozinha)

Não sei, ainda não pensei nisso (9E, 16 anos, Curso EFA B2 Jardinagem)

Secalhar, não sei o futuro, sei lá se arranjo trabalho! (7D, 16 anos, curso EFA B3 El)

Talvez sim (29D, 17 anos, Curso EFA B3 EI)

Não sei, talvez consiga arranjar trabalho (7C, 18 anos, Curso EFA B3 Serralharia)

Dentro desta categoria os conteúdos temáticos divergiram em termos resolução vocacional, isto é, dois jovens revelaram não ter objetivos profissionais definidos e outros três apenas se afirmaram indecisos porque "sim" ou porque não sabem os que lhes reserva o futuro. Contudo, outras opiniões revelaram que apesar da indecisão, os cursos apresentavam utilidade para outras trajetórias profissionais. Nas vozes dos jovens:

Não sei, penso que ainda é cedo, quero adquirir o $9^{\circ}$ ano e depois fazer outro curso, talvez o de mecânica (3B, 17 anos, Curso EFA B3 Marcenaria)

Não sei, só quero fazer o curso para ter o $9^{\circ}$ ano e tirar a carta (12D, 16 anos, Curso EFA B3 OMH)

Não sei,sei que pode vir a ajudar em vias financeiras (16E, 17 anos, curso EFA B3 OMH)

\section{Discussão}

$\mathrm{Na}$ leitura de resultados verifica-se que os jovens institucionalizados participantes, na sua maioria $(n=11)$ eram de nacionalidade portuguesa, tinham a média de idades situada nos 16 anos, correspondendo esta idade à fase de desenvolvimento marcada pela adolescência. A fase de adolescência dos jovens institucionalizados participantes é caracterizada por "experiências de vida destruturadas, num sistema social de inter-relações desajustadas ao desenvolvimento de uma identidade pró-social" (Martins, 2015, p. 159). Neste sentido, as trajetórias escolares destes jovens correspondentes às suas habilitações académicas verificaram-se aquém do que seria esperado para a sua idade. Isto é, a maioria dos jovens participantes frequentavam cursos EFA para aquisição de equivalência ao $3^{\circ}$ Ciclo do Ensino Básico ( $9^{\circ}$ ano de escolaridade), o qual em trajetórias escolares regulares já estaria concluído aos 16 anos de idade. Objetivamente, a maioria dos participantes $(n=12)$ tinham completado o $2^{\circ}$ Ciclo do Ensino Básico ( $6^{\circ}$ ano de escolaridade) e, por isso, frequentavam cursos EFA de tipologia B3. 
$\mathrm{Na}$ avaliação aos cursos EFA, os jovens participantes revelaram opiniões divergentes, em termos de (des)interesse, utilidade e indecisão, relativamente aos cursos EFA frequentados servirem de ajuda à escolha de uma futura profissão. O interesse, projetado na revelação de objetivos definidos para um futuro profissional, em relação aos cursos EFA frequentados alguns jovens revelaram tê-lo explicitamente com a resposta afirmativa "sim". No entanto, alguns destes jovens revelaram o seu interesse associado à utilidade dos cursos EFA, quer em termos de estes se constituírem como (a) forma de completar o percurso escolar interrompido $(n=1)$, quer (b) como forma de conseguir trabalho no futuro $(n=4)$.

Das vozes que os alunos trazem sobre os cursos fica claro que permitem aceder a uma profissão futura, sendo uma oportunidade de terminar uma escolaridade e assim não ficar numa situação futura de marginalização e exclusão social, ou seja, um momento para (re)encontrar um sentido para a visão sobre si mesmo. Os cursos, pelo menos para alguns destes jovens que frequentam os centros, ao permitir-lhes descobrir novas competências e capacidades criam-Ihes janelas de oportunidade que os capacitarão para fugir a uma trajetória marcada de insucessos escolares antes da entrada nos centros.

A maioria dos jovens $(n=8)$ revelou estar indeciso em relação ao que fazer com os cursos que frequentavam, por várias razões, nomeadamente por não revelar objetivos profissionais futuros definidos $(n=3)$. Contudo, algumas das vozes indecisas atribuíram utilidade aos cursos frequentados. Nestes casos, à semelhança dos jovens que se revelaram interessados, isto é, com objetivos profissionais definidos, as opiniões emergentes dos jovens indecisos revelaram que se tratavam de cursos com utilidade (a) para conseguir trabalho $(n=2)$ e (b) para conhecer outros cursos e profissões $(n=2)$.

As vozes dos alunos sugerem que não é linear o sucesso. Nestes casos importa pensar ser necessário existir "conselheiros", ou seja, professores com preparação nesta problemática da carreira ou outros profissionais como psicólogos, que possam desenvolver metodologias de aconselhamento com soluções investidas pelos jovens.

De um modo geral, apesar dos jovens estarem pouco definidos em termos de objetivos futuros para uma profissão, estes percecionam a frequência de cursos EFA como a possibilidade de se continuarem a valorizar e de terem melhores oportunidades para ingressar no mercado de trabalho. Outros estudos realizados em centros educativos portugueses (e.g., Manso, 2006; Manso \& Almeida, 2009, 2010) referem que, de um modo geral, os jovens institucionalizados em centros educativos, reconhecem e valorizam a possibilidade de adquirir competências escolares e de cariz profissional como portal acesso e/ou continuação da trajetória escolar, bem como de acesso a uma via profissional especializada. As dinâmicas pedagógicas veiculadas nos centros educativos portugueses pretendem proporcionar aos jovens institucionalizados, com baixos níveis de escolarização (Duarte-Fonseca, 2005), a aquisição de competências no quadro da formação escolar e profissional, criando condições para adquirir conhecimentos especializados para o desempenho de uma profissão.

\section{Conclusões}

Ao longo deste texto discutiu-se como a Psicologia Vocacional redefiniu o seu modelo concetual e a sua perspetiva de atuação. Se antes a preocupação estava centrada em apoiar os indivíduos a escolher uma profissão e a desenvolverem as suas carreiras, atualmente centra-se em apoiar os indivíduos a construir as suas trajetórias de vida, as de índole pessoal a par de uma profissão.

O novo paradigma é um modelo que pretende responder às necessidades da sociedade marcada pela diversidade e mudanças rápidas no âmbito socioeconómico e tecnológico (Cardoso, 2011).Numa perspetiva com origem no pensamento pos-moderno Life Design ou Construção da vida é o paradigma atual da Psicologia Vocacional. É um paradigma que se centra o desenvolvimento dos indivíduos, numa perspetiva de aprendizagem ao longo da vida, de modo a ajudar os sujeitos a "projectar a vida com autoria ou marca pessoal, o qual, tal como nas artes, requer compreensão de todo o ciclo de vida, trabalho, modelagem, ajustes interactivos e mesmo re-designing ou reconstrução" para fazer face às mudanças que possam surgir (Taveira, 2011, p.74).

As trajetórias de vida dos indivíduos são atualmente entendidas como um ciclo aberto e adaptável às circunstâncias contextuais que os indivíduos integram, em que são necessários (des)ajustes para a projeção da vida e formação da identidade, nomeadamente a identidade vocacional. Assim, o novo paradigma Life Design, assente nos modelos de orientação e de construção de carreira do século XX, mas com reflexão nas necessidades socioeconómicas do atual século $X X I$, necessita ser desenvolvido com indivíduos jovens para que estes se tornem conscientes da necessidade de se desenvolverem flexíveis aos desafios que terão de enfrentar (Teixeira \& Barros, 2011).

Os indivíduos elaboram o seu estilo de vida e as suas condutas de acordo com a natureza das interações que estabelecem nos seus contextos sociais. Neste sentido, as instituições a que os indivíduos pertencem (e.g., família, amigos, escola) regulam as relações entre os indivíduos, legitimando ou invalidando-as (Scott, 2013). Com efeito, os centros educativos, como instituições responsáveis pelos jovens institucionalizados, sob a execução de MTE de internamento, possibilitam que os jovens interajam mediante a prática de atividades de educação e formação. Pelo que, se por um lado os centros educativos, como instituições destinadas ao acolhimento, sob a forma de internamento, de jovens com trajetórias delinquentes, possam ser espaços de segregação social, por outro, são espaços que se orientam mediante condições institucionais, configuradas com isolamento, segurança e atividades pedagógicas reguladas, afastando os jovens de influências antigas, com o objetivo de influenciar o comportamento dos jovens para o exercício de uma vida responsável (Pane \& Rocco, 2014).

Os jovens institucionalizados em centros educativos envolvem-se e exploram o seu futuro profissional através da frequência de cursos EFA de tipologia B2 e B3. Através dos cursos EFA, os jovens têm a oportunidade de continuar a 
trajetória escolar interrompida, adquirindo algumas competências académicas e uma certificação profissional para o exercício de uma profissão. Neste sentido, os jovens participantes avaliaram a formação EFA que recebiam como pouco interessante, mas com utilidade vocacional, no que se refere à possibilidade de encontrar trabalho, como por exemplo, em práticas laborais que envolviam por exemplo os cursos de cozinha e IRC.

$\mathrm{Na}$ literatura é evidente que a trajetória escolar influencia as escolhas de vida durante a transição da adolescência para a vida adulta (e.g., Eccles, Templeton, Barber, \& Stone, 2003; Garrett \& Eccles, 2009; Guichard, 2012). Sabendo que a adolescência é uma fase de desenvolvimento, por excelência, na qual os jovens desenvolvem a identidade num processo dinâmico entre indecisão, exploração e grau de investimento em compromissos vocacionais (Taveira \& Campos, 1987; Taveira, 2000), a possibilidade da frequência dos cursos EFA para jovens institucionalizados em centros educativos pode representar uma medida facilitadora de envolvimento escolar e, por sua vez, de exploração vocacional.

As oportunidades disponíveis para os jovens institucionalizados em centros educativos centram-se em dotar os indivíduos de competências educacionais, laborais ou profissionais para que os seus padrões de pensamento e relacionamento interpessoal se alterem (Gonçalves, 2007). A institucionalização de jovens prioriza a redução da exposição aos fatores de risco e a aquisição de competências académicas e profissionalizantes através do envolvimento escolar em cursos EFA, com vista à alteração de comportamentos antisociais, para a plena reinserção social destes jovens. Considerando que o envolvimento escolar surge quando o indivíduo tem interesse ou percebe o valor e a aplicabilidade do que aprende (Sinclair, Christenson, Lehr, \& Anderson, 2003) os cursos EFA podem ser uma via de acesso a trajetórias de vida pro-sociais. Apesar, deste estudo ter tido a participação de apenas 15 jovens, institucionalizados em centros educativos portugueses, não permitindo explorar as perceções da população destes jovens acerca da avaliação dos cursos EFA, é possível perceber que alguns cursos EFA (e.g., cozinha, IRC) são avaliados com utilidade para encontrar trabalho. Neste sentido, considera-se importante em estudos futuros alargar o número de participantes para se conseguir um melhor mapeamento dos cursos que possam ser identificados com maior aplicabilidade ao mercado de trabalho português e, desta forma, adequar a formação destes jovens institucionalizados à (re)inserção social positiva e sustentável a médio e longo prazo.

Sendo o paradigma Life Design um modelo recente, é necessário dinamizar programas de intervenção para a orientação vocacional e desenvolvimento de carreira que acompanhem as formas de educação e as trajetórias de construção de vida dos indivíduos jovens e institucionalizados em centros educativos, designadamente através do trabalho ou das ocupações que terão de vir a realizar ou que vão experienciando, com a finalidade de inserção social e principalmente de encontrar realização entre a vida pessoal e o trabalho (Martins, 2015). Esta ideia é reforçada com o trabalho de Silva (2016), no sentido em que é necessário dinamizar estratégias potenciadoras de orientação profissional de modo a que indivíduo aprendente consiga vir a "ser o mais bem-sucedido possível” (p. 243), prevenindo-se comportamentos de marginalização e exclusão social.

\section{Referências}

Alves, M.G. (2012). Sociologia da Educação. Aprendizagem ao longo da vida e transições educativas e profissionais: os diplomados de ensino superior em tempos de incerteza. Atas do VII Congresso português de Sociologia. Porto: Universidade do Porto. Recuperado: 2 set. 2016. Disponível: http://www.aps.pt/ vii_congresso/papers/finais/PAP0383_ed.pdf

Alves, N. (2006). Socialização escolar e profissional dos jovens: projectos, estratégias e representações. Lisboa: Educa.

Amado, J.; Ribeiro, F.; Limão, I.; Pacheco, V. (2003). A Escola e os Alunos Institucionalizados. Lisboa: Departamento da Educação Básica, Ministério da Educação.

Amorim, H. (2013). O tempo de trabalho: uma chave analítica. Sociedade e estado, 28(3), 503-518. Recuperado: 13 maio 2016. Disponível: https://dx.doi.org/10.1590/S010269922013000300003

Andrade, J.; Meira, J.; Vasconcelos, Z. (2002). O processo de orientação vocacional frente ao século XXI: perspectivas e desafios. Psicologia, Ciência e Profissão, 22(3), 46-53. Recuperado: 28 set. 2016. Disponível: http://dx.doi.org/10.1590/ S1414-98932002000300008

Bauman, Z. (2001). Modernidade líquida. Rio de Janeiro: Zahar.

Bardin, L. (2011). Análise de Conteúdo. Lisboa: Edições 70

Bradagi, M.; Lassance, M.C.; Paradiso, A.; Menezes, I. (2006). Escolha profissional e inserção no mercado de trabalho: percepções de estudantes formandos. Psicologia Educacional e Escolar, 10(1), 70-82. Recuperado: 26 jul. 2016. Disponível: http:// dx.doi.org/10.1590/S1413-85572006000100007

Bogdan, R.; Biklen, S. (1996). Investigação Qualitativa em Educação: Uma Introdução à teoria e aos Métodos.Porto: Porto Editora.

Calheiros, M.; Garrido, M.; Lopes, D.; Patricío, J.(2015). Social images of residential care: How children, youth and residential care institutions are portrayed? Children and Youth Services Review, 55, 159-169. Recuperado: 13 maio 2016. Disponível: http://doi. org/10.1016/j.childyouth.2015.06.004

Cardoso, P. (2011). Construção de Si na Construção da Vida: Comentário a Savickas et al. Revista Portuguesa de Psicologia, 42, 83-91, 2011. 
Decreto-Lei $n^{\circ}$ 323-D/2000 de 20 de Dezembro (2000, 20 de dezembro). Regulamento geral e disciplinar dos centros educativos. Portugal: Procuradoria-Geral Distrital de Lisboa. Recuperado: 9 jun. 2016 Disponível: http://www.pgdlisboa.pt/leis/ lei_mostra_articulado.php?nid=544\&tabela=leis

Despacho n. ${ }^{\circ}$ 23038/2009 de 20 de outubro de 2009 (2009, 20 de outubro). Enquadramento das ofertas de educação e formação para os jovens integrados em Centros Educativos. Portugal: Ministérios da Justiça, do Trabalho e da Solidariedade Social e da Educação. Recuperado: 9 jun. 2016. Disponível: https://www. cnpdpcj.gov.pt/pagina $\cdot$ aspx?f=3\&back=1\&mid=5069\&id=11553

Duarte-Fonseca, A.C. (2005). Internamento de Menores DelinquentesA lei Portuguesa e os seus Modelos: Um Século de Tensão entre Protecção e Repressão, Educação e Punição. Coimbra: Coimbra Editora.

Duarte, M.E. (2009). Um século depois de Frank Parsons: escolher uma profissão ou apostar na psicologia da construção da vida? Revista Brasileira de Orientação Profissional, 10(2), 5-14. Recuperado: 15 out. 2016 Disponível: htttp://pepsic.bvsalud.org/scielo.php?pid=S16 $7933902009000200003 \&$ script=sci_arttext\#aut

Duarte, M.E.; Lassance, M.C.; Savickas, M.L.; Nota, L.; Rossier, J.; Dauwalder, J.; Guichard, J.; Soresi, S.; Van Esbroeck, R.; Van Vianen, A. (2010). A Construção da Vida: Um Novo Paradigma para Entender a Carreira no Século XXI. Interamerican Journal of Psychology, 44(2), 392-406, Recuperado: 15 out. 2016 Disponível: http://www.redalyc.org/articulo.oa?id=28420641020.

Eccles, J.; Templeton, J.; Barber, B.; Stone, M. (2003). Adolescence and emerging adulthood: The critical passage ways to adulthood. IN: Bornstein, M.H.; Davidson, L.; Keyes, C.; Moore, K.A. (Orgs.), Well-being: Positive development across the life course. Crosscurrents in contemporary psychology (pp. 383-406). Mahwah, NJ, US: Lawrence Erlbaum Associates Publishers. Recuperado: 5 jan. 2016. Disponível: http://www.rcgd.isr.umich. edu/garp/articles/eccles03b.pdf

Frankl, V.E. (1988). The Will to Meaning: Foundations and Applications of Logotherapy. Nova lorque: Meridian Books.

Garrett, J.L.; Eccles, J.S. (2009). Transition to Adulthood: Linking LateAdolescent Lifestyles to Family and Work Status in the Mid-Twenties. IN: Schoon, I.; Silberseisen, R.K. (Orgs.), Transitions from School to Work: Globalization, Individualization, and Patterns of Diversity (pp. 243-264). New York, NY: Cambridge University Press.

Gonçalves, R.A. (2007). Promover a mudança em personalidades anti-sociais: Punir, tratar e controlar. Análise Psicológica, 4(25), 571-583, 2007. Recuperado: 5 maio 2016. Disponível: http://www. scielo.mec.pt/pdf/aps/v25n4/v25n4a03.pdf

Guichard, J. (2012). How to Help Emerging Adults Develop their Career and Design Their Lives in an Age of Uncertainty? Cypriot Journal of Educational Sciences, 7(4), 298-310. Recuperado: 13 maio 2016. Disponível: http://www.world-education-center.org/ index.php/cjes/article/view/914

Guichard, J. (2005). Life-long self construction. International Journal for Educational and Vocational Guidance, 5, 111-124. doi: 10.1007/ s10775-005-8789-y.

Hirschi, A. (2012). Vocational identity trajectories: Differences in personality and development of well-being. European Journal of Personality, 26(1), 2-12.

Lei $n^{\circ}$ 166/99 de 14 de Outubro (1999, 14 de outubro). Lei Tutelar Educativa. Portugal: Diário da república, I, Série A. Recuperado: 22 out. 2016. Disponível: http://www.dre.pt/ pdf1s/1999/09/215A00/63206351.pdf

Levinson, D. (1990). A theory of Life structure development in adulthood. IN: Alexander; C.; Langer, E. (Orgs), Higher stages of human development: perspectives on adult growth (pp. 35-53). New York: Oxford University Press.

Manso, A. (2006). Educação para o direito: representações sociais de jovens institucionalizados em centro educativo (Dissertação de mestrado). Braga: Instituto de Estudos da Criança, Universidade do Minho.

Manso, A., \& Almeida, A. (2009). Representações sociais de jovens institucionalizados em Centro Educativo: Perspectivas sobre a educação para o direito. Ousar Integrar-Revista de Inserção Social e Prova, 2, 31-42.

Manso, A., \& Almeida, A. (2010). “... E depois o que é querem que faça?" Educar para o Direito: Pontes de ligação do centro educativo à comunidade. Educação, Sociedade \& Culturas, 30, 23-40. Recuperado: 2 set. 2016. Disponível: http://www.fpce.up.pt/ ciie/revistaesc/ESC30/resumosESC30/Manso_resumo.pdf

Martins, D. (2015). Desenvolvimento da identidade vocacional de jovens institucionalizados em centros educativos portugueses. (Tese de Doutoramento). Instituto de Educação, Universidade de Lisboa. Recuperado: 6 set. 2016. Disponível: http://hdl.handle. net/10451/18259

Martins, D.; Carvalho, C. (2015). Feedback do Professor: Discurso Orientador na Autorregulação e Desenvolvimento Vocacional de Jovens Institucionalizados. IN: Ferreira, C. (Org.), Atas do II Colóquio Cabo-Verdiano de Educação - CEDU2015: Políticas e práxis da Educação nas perspetivas e em contextos póscoloniais (pp.26-37). Praia: Edições Uni-CV. Recuperado: 23 set. 2016. Disponível: http://www.unicv.edu.cv/images/edicoes/Atas_ CEDU2015.pdf

Martins, D.; Carvalho C. (2013). A Identidade Vocacional de Jovens Institucionalizados em Centros Educativos: Um Olhar na $(\mathrm{Re})$ Educação Em Portugal. Revista Eletrônica de Educação, 7(3), 25-39. Recuperado: 23 set. 2016 Disponível: http://www.reveduc. ufscar.br/index.php/reveduc/article/view/652 
Pacheco, J.A.; Pestana, T.; Figueiredo, J.; Martins, D. (2014). Globalização, currículo e aprendizagem. Para uma análise crítica das práticas curriculares em contextos diferenciados. In: T. Estrela \& cols. (Orgs.), Educação, Economia e Território: O lugar da educação no desenvolvimento. Atas do XXI Colóquio da Secção Portuguesa da AFIRSE. Lisboa: Instituto da Educação da Universidade de Lisboa.

Pais, M.J. (1999). Traços e Riscos de Vida. Uma Abordagem Qualitativa a Modos de Vida Juvenis. Porto: Ambar.

Pane, D.M.; Rocco, T.S. (2014). Transforming the School-to-Prison Pipeline. Lessons from the Classroom. The Netherlands: Sense Publishers. Recuperado: 12 set. 2016 Disponível: https://www. sensepublishers.com/media/1823-transforming-the-school-toprison-pipeline.pdf

Quintas, H. (2008). Educação de Adultos: vida no currículo e currículo na vida. Lisboa: Agência Nacional para a Qualificação.

Savickas, M.L. (2012). Life Design: A Paradigm for Career Intervention in the 21st Century. Journal of Counseling \& Development, 90, 1319. doi: https://doi.org/10.1111/j.1556-6676.2012.00002.x

Savickas, M., Nota, L., Rossier, J., Dauwalder, J., Duarte, M., Guichard, J., Soresi, S., Esbroeck, R., Vianen, A. (2009). Life designing: A paradigm for career construction in the 21st century. Journal of Vocational Behavior, 75, 239-250. doi:10.1016/j.jvb.2009.04.004

Savickas, M. L. (2005). The Theory and Practice of Career Construction. In S. D. Brown and R. W. Lent (Ed), Career Development and Counseling: Putting Theory and Research to Work (pp.42-70). Hoboken, NJ: John Wiley \& Sons.

Scott, W.R. (2013). Institutions and organizations: Ideas, interests, and identities (4th ed). Thousand Oaks, California: Sage Publications, Inc.

Sloutsky, V. (1997). Institutional care and developmental outcomes of 6 and 7 year-old children: A contextualist perspective. International Journal of Development, 20(1), 131-151.
Silva, L. (2016). Estudo sobre a Orientação Vocacional e Profissional - Escolhas. Psicologia Escolar e Educacional, 20(2), 239244. Recuperado: 5 out. 2016. Disponível: http://dx.doi. org/10.1590/2175-3539/2015/0202957

Sinclair, M., Christenson, S., Lehr, C., \& Anderson, A. (2003). Facilitating Student Engagement: Lessons Learned from Check Connect Longitudinal Studies. The California School Psychologist, 8, 29 - 41. Recuperado: 5 maio 2016. Disponível http://education.ucsb.edu/school-psychology/CSP Journal/PDF/ CSP2003(volume_8).pdf

Souto, G.P. (2010). Direitos Humanos e Justiça juvenil: onde começam os direitos dos infractores? Uma abordagem internacional. Ousar integrar- Revista de reinserção social e prova, 7, 23-33

Super, D.E. (1953). A theory of vocational development. American Psychologist, 8, 185-190.

Taveira, M.C. (2011). Análise crítica do modelo life designing: contributos para reflexão. Revista Portuguesa de Psicologia, 42, 71-81. Recuperado: 23 out. 2016. Disponível: http://hdl.handle. net/1822/14194

Taveira, M.C. (2000). Exploração e Desenvolvimento Vocacional de Jovens: Estudo sobre as Relações entre a Exploração, a Identidade e a Indecisão Vocacional. (Tese de doutoramento publicada). Centro de Estudos em Educação e Psicologia, Instituto da Educação e Psicologia da Universidade do Minho, Braga.

Taveira, M.C.; Campos, B.P. (1987). Identidade Vocacional de Jovens: Adaptação de uma Escala (DISI-O). Cadernos de Consulta Psicológica, 3, 55-67.

Teixeira, M.O.; Barros, A.F. (2011). Orientação e Educação: Que Relação no Paradigma do Life Design?. Revista Portuguesa de Psicologia, 42, 93-100.

\section{Sobre as autoras}

Dulce Martins (dulce.sofia.martins@iscte-iul.pt)

Instituto Universitário de Lisboa (ISCTE-IUL), Centro de Investigação e Intervenção Social, Lisboa, Portugal. https://orcid.org/0000-0003-1429-0523

Carolina Carvalho (cfcarvalho@ie.ulisboa.pt)

Professora Auxiliar no UIDEF, Instituto de Educação da Universidade de Lisboa, Portugal. https://orcid.org/0000-0003-1793-2288

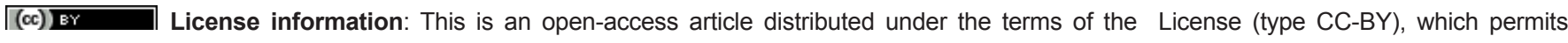
unrestricted use, distribution and reproduction in any medium, provided the original article is properly cited. 